\section{Towards a more comprehensive classification of satellite viruses}

\section{Mart Krupovic and Virginija Cvirkaite-Krupovic}

Our recent Comment on the nature and place of the so-called virophages in the viral world (Virophages or satellite viruses? Nature Rev. Microbiol. 9, 762-763 (2011)) ${ }^{1}$ has caught the attention of researchers favouring the virophage concept and initiated a debate on this matter. We welcome the Correspondence article from Desnues and Raoult (Virophages question the existence of satellite viruses. Nature Rev. Microbiol. 16 Feb 2012 (doi:10.1038/ nrmicro2676-c3) ${ }^{2}$ - which follows a similar Correspondence article from Matthias Fischer ${ }^{3}$, to which we have responded previously ${ }^{4}$ - and take this occasion to reiterate our conclusion that the general biological properties and behaviour of Sputnik and Mavirus are not at all novel in the virosphere and have been previously described for satellite viruses ${ }^{1,4}$.

In their Correspondence article, Desnues and Raoult again point out the allegedly unique features of Sputnik and Mavirus: complexity of virion and genome organizations, lack of sequence similarity to other currently isolated viruses, structural relationship to viruses with double- $\beta$-barrel capsid proteins ${ }^{5,6}$, effect on helper virus production and host cell survival, intracellular localization and specific genome expression signals ${ }^{2}$. All these arguments we have addressed and refuted in our two previous communications ${ }^{1,4}$.
Desnues and Raoult also argue that the parallels we have drawn between the infection characteristics of the Sputnik-mamavirus and satellite tobacco necrosis virus (STNV)-TNV systems ${ }^{1,4}$ are inappropriate - in their words, "equivalent to comparing cows and apples" because unlike for Sputnik-mamavirus, "the replication cycle of the STNV-TNV couple does not have a transcription stage" (REF. 2). However, contrary to this belief, replication and transcription in many positive-sense RNA viruses are discernible processes and, in fact, can be uncoupled experimentally in members of the family Tombusviridae ${ }^{7}$, the viral family to which TNV belongs. It is also not true that "RNA-dependent RNA polymerase (RdRp) ... is a typical viral enzyme that is not found in eukaryotic, bacterial or archaeal genomes", as functional RdRps, albeit non-homologous to the viral enzymes, are encoded in fungal, nematode and plant genomes ${ }^{8}$. More generally, the reluctance of the authors to consider the parallels between (satellite) viruses with RNA and DNA genomes is surprising, if not alarming. It is also not clear how "Virophages question the existence of satellites" (the title of their Correspondence article); the existence of satellite viruses is an unquestionable fact.

Furthermore, although classical satellite viruses, both those with single-stranded
RNA genomes (STNV) and single-stranded DNA genomes (adeno-associated virus), typically decrease the production of their helper viruses to non-detectable amounts (see the section entitled 'Effect of the satellite virus on the helper virus' in our Comment) ${ }^{1}$, Desnues and Raoult point out that in the case of STNVTNV the production of the helper virus is sometimes increased during a co-infection?. However, this is not a typical situation. It has been suggested that under certain circumstances STNV alters host cell physiology, rendering the cell susceptible to TNV infection (that is, increasing the number of TNVsusceptible cells $)^{9}$. The effect on helper virus production at the infected-cell level would nevertheless be negative. More generally, the extent of the effect a satellite virus has on its helper virus largely depends on the ratio of the two viruses (satellite particles per helper particle) during a co-infection. For MavirusCafeteria roenbergensis virus and Sputnikmamavirus, this ratio has not been estimated (at least, such estimates have not been reported $)^{10,11}$, precluding meaningful comparisons with other, more comprehensively studied satellite virus-helper virus systems.

In our Comment we pointed out the shortcomings associated with the current classification scheme of satellite viruses - or, more accurately, the lack of one ${ }^{1}$. (Notably, in the ninth report of the International Committee on Taxonomy of Viruses (ICTV), Sputnik is classified together with other satellite viruses $^{12}$ ). In their Correspondence article, Desnues and Raoult also criticize the ICTV classification of satellite viruses and attempt "to go beyond semantics" by suggesting the introduction of "a new group called 'viruses

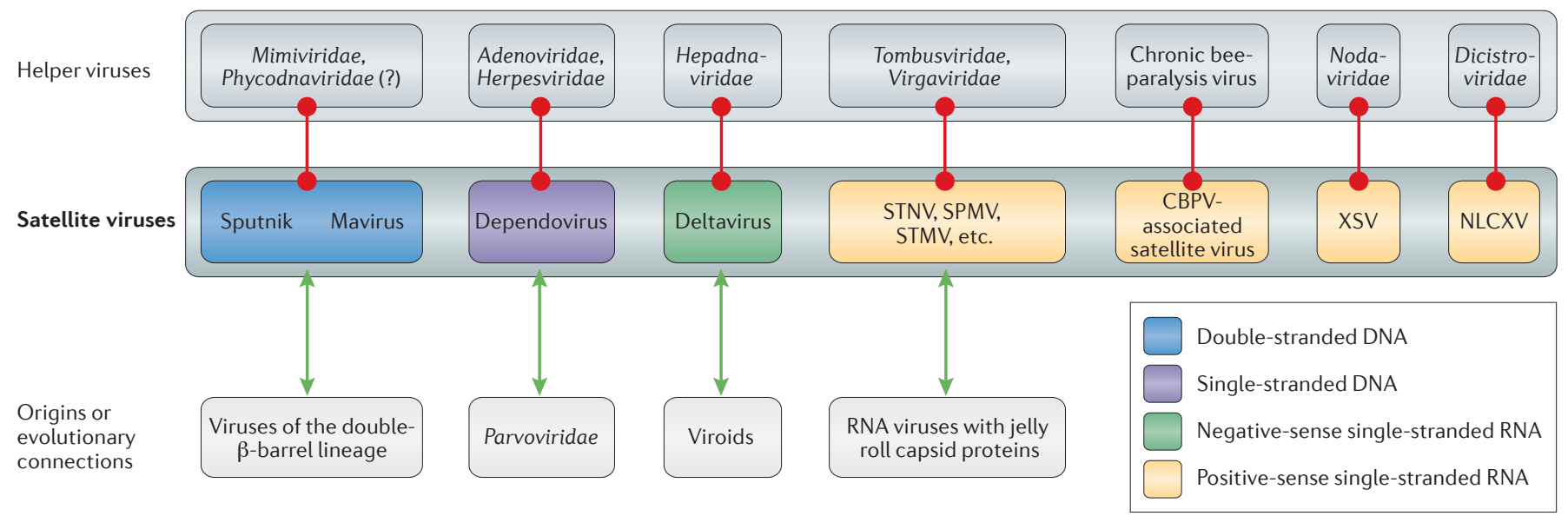

Figure 1 | Satellite viruses and their classification. The currently known satellite viruses are grouped into family-level taxa (boxes) on the basis of available sequence and structural information. Satellite virus groups are coloured according to their genome types. Associated helper viruses are indicated above each group of satellite viruses. In addition, possible evolutionary relationships to other viruses or viroids are shown in the lower row. SPMV, satellite panicum mosaic virus; STMV, satellite tobacco mosaic virus; XSV, extra small virus; NLCXV, Nilaparvata lugens commensal X virus; $\mathrm{CBPV}$, chronic bee-paralysis virus. 


\section{CORRESPONDENCE}

of Viruses', encompassing virophages and traditional satellite RNA viruses"; in other words, they propose to rename the currently existing class 'satellite viruses' as 'viruses of Viruses'. Instead, we propose to adopt, in our opinion a more meaningful scheme for classification of satellite viruses into family-level (and perhaps higher-level) taxa (FIG. 1). This approach is compatible with the current ICTV classification scheme for 'autonomous' viruses and would be a firm step towards bringing conceptual order to the classification of satellite viruses and the virosphere in general ${ }^{13}$.

Mart Krupovic and Virginija Cvirkaite-Krupovic are at the Institut Pasteur, Department of Microbiology, 25 rue du Dr. Roux, 75015 Paris, France.

Correspondence to M.K. e-mail:krupovic@pasteur.fr

1. Krupovic, M. \& Cvirkaite-Krupovic, V. Virophages or satellite viruses? Nature Rev. Microbiol. 9, 762-763 (2011).

2. Desnues, C. \& Raoult, D. Virophages question the existence of satellites. Nature Rev. Microbiol. 16 Feb 2012 (doi: 10.1038/nrmicro2676-c3)
3. Fischer, M. G. Sputnik and Mavirus: more than just satellite viruses. Nature Rev. Microbiol. 10, 78 (2012).

4. Krupovic, M. \& Cvirkaite-Krupovic, V. Sputnik and Mavirus: not more than satellite viruses. Nature Rev. Microbiol. 10, 78 (2012)

5. Sun, S. et al. Structural studies of the Sputnik virophage. J. Virol. 84, 894-897 (2010).

6. Krupovic, M. \& Bamford, D. H. Virus evolution: how far does the double $\beta$-barrel viral lineage extend? Nature Rev. Microbiol. 6, 941-948 (2008).

7. Wu, B. \& White, K. A. Uncoupling RNA virus replication from transcription via the polymerase: functional and evolutionary insights. EMBO J. 26 , 5120-5130 (2007).

8. Ahlquist, P. RNA-dependent RNA polymerases, viruses, and RNA silencing. Science 296, 1270-1273 (2002)

9. Kassanis, B. Properties and behaviour of a virus depending for its multiplication on another. J. Gen. Microbiol. 27, 477-488 (1962).

10. Fischer, M. G. $\&$ Suttle, C. A. A virophage at the origin of large DNA transposons. Science 332, 231-234 (2011).

11. La Scola, B. et al. The virophage as a unique parasite of the giant mimivirus. Nature 455, 100-104 (2008).

12. King, A. M. Q., Adams, M. J., Carstens, E. B. \& Lefkowitz, E. J. Virus Taxonomy. Ninth Report of the International Committee on Taxonomy of Viruses (Elsevier Academic, London, 2012).

13. Krupovic, M. \& Bamford, D. H. Order to the viral universe. J. Virol. 84, 12476-12479 (2010).

Competing interests statement

The authors declare no competing financial interests. 